\title{
The incidence of laryngeal cancer in Iran: A systematic review and meta- analysis
}

\author{
Soheil Hassanipour ${ }^{\mathrm{a}, \mathrm{b}}$, Hamed Delam ${ }^{\mathrm{c}}$, Hossein-Ali Nikbakht ${ }^{\mathrm{d}, \mathrm{b}}$, Elham Abdzadeh $^{\mathrm{e}}$, \\ Hamid Salehiniya ${ }^{\mathrm{f}, \mathrm{g}}$, Morteza Arab-Zozani ${ }^{\mathrm{h}}$, Haleh Ghaem ${ }^{\mathrm{i}, *}$ \\ ${ }^{a}$ Gastrointestinal \& Liver Diseases Research Center, Guilan University of Medical Sciences, Rasht, Iran \\ ${ }^{\mathrm{b}}$ Student Research Committee, Shiraz University of Medical Sciences, Shiraz, Iran

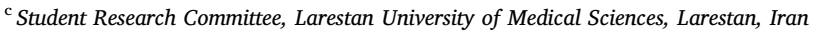 \\ ${ }^{\mathrm{d}}$ Social Determinants of Health Research Center, Health Research Institute, Babol University of Medical Sciences, Babol, Iran \\ ${ }^{\mathrm{e}}$ Department of Biology, Faculty of Science, University of Guilan, Rasht, Iran \\ ${ }_{\mathrm{f}}^{\mathrm{f}}$ Zabol University of Medical Sciences, Zabol, Iran \\ ${ }^{\mathrm{g}}$ Department of Epidemiology and Biostatistics, Tehran University of Medical Sciences, Tehran, Iran \\ ${ }^{\mathrm{h}}$ Iranian Center of Excellence in Health Management, School of Management and Medical Informatics, Tabriz University of Medical Sciences, Tabriz, Iran \\ ${ }^{\mathrm{i}}$ Research Center for Health Sciences, Institute of Health, Epidemiology Department, School of Health, Shiraz University of Medical Sciences, Shiraz, Iran
}

\section{A R T I C L E I N F O}

\section{Keywords:}

Incidence

Laryngeal cancer

Iran

Epidemiology

Systematic review

\begin{abstract}
A B S T R A C T
Objectives: The incidence of larynx cancer (LaC) from different areas of Iran were reported. Nevertheless, there is no available systematic reviews in this regard. Therefore, the present systematic review carried out to estimate the incidence rate of $\mathrm{LaC}$ among Iranian people.

Method: This systematic review was performed according to the Preferred Reporting Items for Systematic Reviews and Meta-Analysis (PRISMA) in October 2017. A search was concluded using Medline/PubMed, Embase, ISI web of knowledge, Scopus, ScienceDirect, and Google scholar for international papers and four national databases (Scientific Information Database, MagIran, IranMedex, and IranDoc) for Persian papers. The incidence rate of $\mathrm{LaC}$ was calculated using random effect model.

Result: An aggregate of 166 papers were retrieved in the primary search of the databases. Further screening and advanced refinement of the retrieved studies produced 13 studies totally. The age-standardized rate (ASR) of LaC was 2.70 , 95\% CI (1.86-3.53) and 0.46, 95\% CI (0.31-0.61) in males and females, respectively.

Conclusion: In comparison to other parts of the world, the incidence of $\mathrm{LaC}$ was lower in Iran. Afterwards, further studies are necessary to outline the exact incidence rate and the trend of LaC in Iran.
\end{abstract}

\section{Introduction}

Larynx cancer $(\mathrm{LaC})$ is the second most common cancer of the head and neck region. ${ }^{1,2}$ About $30-40 \%$ of malignant head and neck tumors and $1 \%-2.5 \%$ of all cancer cases are related to $\mathrm{LaC} .{ }^{3} \mathrm{LaC}$ is approximately the 20th most common cancer worldwide, with more than 150,000 new cases diagnosed annually. ${ }^{4}$

The number of new cases diagnosed with laC in the United States is 4.5 per 100,000 people per year. ${ }^{5}$ In total, the incidence rate of laC is low throughout the world. However, countries such as Brazil, France, Italy, Spain, India and parts of Southeast Asia have higher incidence rates of laC than other parts of the world. ${ }^{6}$

The incidence rate of laC is higher in men than in women, in whites than in blacks, and in urban than in rural areas. ${ }^{6}$ Studies have shown that laC has been more common in Eastern Asia than in Western Asia. One of the reasons for high incidence rate of this cancer in the West Asia is the higher rate of tobacco consumption in this area compared to the East Asia. ${ }^{7}$

$\mathrm{LaC}$ is a multifactorial disease influenced by environmental and liferelated factors. Cigarette smoking and alcohol consumption have been identified as two major risk factors for this cancer, being responsible for most cases of laC in developed countries. ${ }^{4,8}$

The first study on cancer incidence in Iran dates back to the 1970s. The study was aimed to investigate cancer incidence in the Caspian littoral region. ${ }^{9}$ The results of the epidemiological studies show that laC is the most common head and neck cancer in Iran, consisting $36 \%$ of all kinds of cancers in this part of the body and still continues to increase. ${ }^{10}$ Other studies also confirm that this cancer is a common head and neck

\footnotetext{
* Corresponding author.

E-mail address: halehghaem.epid@gmail.com (H. Ghaem).
} 
cancer. $^{11}$

Considering the fact that only a few studies have been conducted on the epidemiology of cancers in Iran, ${ }^{12-17}$ there is no accurate data on the incidence of laC. Moreover, it is necessary to access the accurate data and know the incidence rate of laC for planning and evaluating cancer prevention and control programs. Therefore, the present study is conducted to evaluate the age-standardized incidence rate of laC in Iran through a systematic and meta-analysis review.

\section{Methods}

The study was planned and conducted in 2017. The systematic review was conducted using the Preferred Reporting Items for Systematic Reviews and Meta-Analysis (PRISMA) checklist. ${ }^{18}$

\subsection{Search strategy of systematic reviews}

A literature search of published studies were conducted using Medline/PubMed, Embase, ISI web of knowledge, Scopus, ScienceDirect, and Google Scholar as international databases, and Scientific Information Database (SID) (www.sid.ir), MagIran (www. magiran.com), IranMedex (www.iranmedex.com), and Irandoc (www. irandoc.ac.ir) as national databases in October 2017. No time duration limitation was considered. The keywords included: "cancer", "laryngeal cancer", "laryngeal neoplasms", "laryngeal tumor"," laryngeal carcinoma", "cancer of larynx", "neoplasms of larynx", "larynx cancer", "larynx carcinoma", "larynx neoplasms", "larynx tumor", "incidence", "epidemiology" and "Iran". The search strategy in PubMed database show that in appendix 1 . The citation results were then imported into EndNote X5 software (Thomson Reuters, Carlsbad, CA, USA). Thereafter, the studies were checked out by two reviewers independently.

\subsection{Screening of studies}

Screening of studies, extraction of results, and evaluation of quality control of the articles were performed independently by two researchers' Also, a supervisor was appointed to make the final decision in cases where there was lack of agreement between the two assessments.

\subsection{Inclusion and exclusion criteria}

The papers contained clearly reports of the age-standardized rate (ASR) of LaC and obviously description of Iranian populations of any language and time were included. In addition, the papers with the following criteria were excluded: studies which reported prevalence rate, the letter to editor, poster, conference papers, and duplicated studies.

\subsection{Quality assessment}

In order to assess the quality of the articles, a checklist prepared by The Joanna Briggs Institute (JBI) was used. ${ }^{19}$ The purpose of this appraisal is to assess the methodological quality of a study and to determine the extent to which a study has addressed the possibility of bias in its design, conduct and analysis. All papers were evaluated on the basis of data relevance and methodological rigor. The results of Quality assessment presented in Table 1.

\subsection{Statistical analysis}

All the analysis were conducted using STATA software, version 12 (Stata Corp LP, College Station, TX, USA). Statistical heterogeneity was assessed by Cochran's $Q$ statistic (with a significance level of $p \leq 0.1$ ) and $\mathrm{I}^{2}$ statistic (with a significance level of $\geq 50 \%$ ). In the presence of significant heterogeneity among the studies, the Meta-analysis was

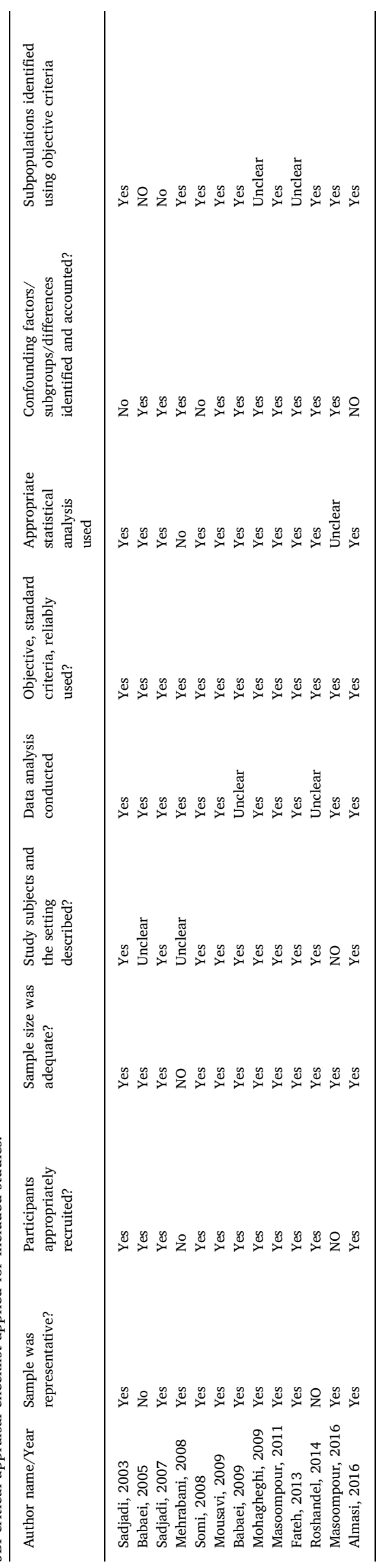




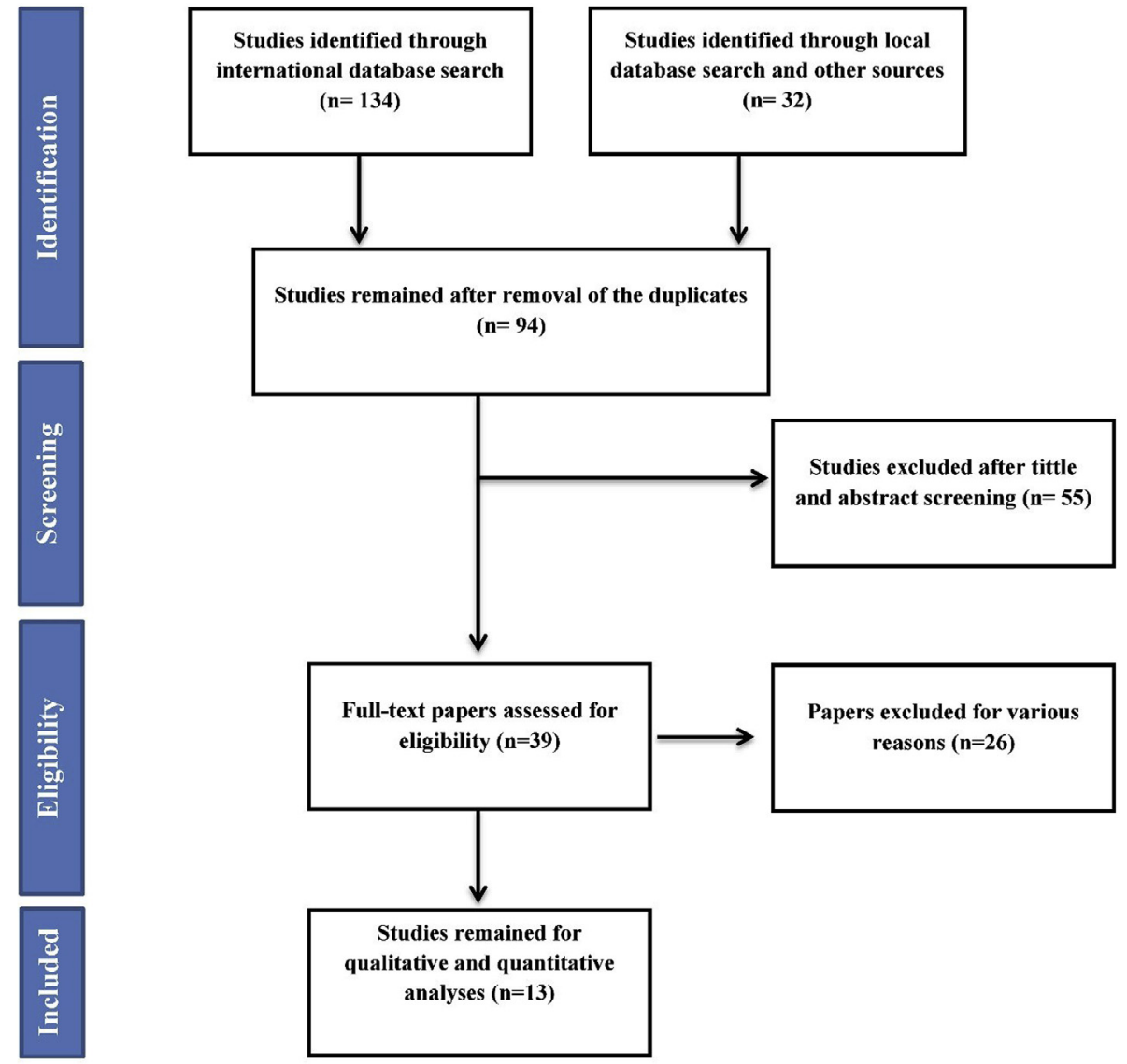

Fig. 1. Flowchart of the included eligible studies in systematic review.

done by random effect model (with inverse variance method) was used. On the other hand, in the case which is not heterogeneous ( $p>0.1$ and $\mathrm{I}^{2}<50 \%$ ), fixed effect model was performed.

\subsection{Risk of bias across studies}

Random effect model was used for minimizing risk of bias across the studies $^{20,21}$

\section{Results}

\subsection{Description of literature search}

The search process and Study selection base on PRISMA flow chart in this systematic review has been outlined in Fig. 1. The literature searches yielded 166 potentially relevant studies from the primary searches. In total, 94 studies met inclusion criteria and entered into the second stage of evaluation. Some studies were excluded for the following reasons: being irrelevant to the topic $(n=37)$, incorrect study population $(n=14)$, duplicate studies $(n=3)$, and insufficient data $(n=7)$. Overall, the review included 13 unique studies.

\subsection{Description of the included studies}

The basic characteristics of the included studies have been summarized in Table 2. According to the geographical area, three studies were conducted in Fars province, ${ }^{22-24}$ two in Ardabil province, ${ }^{25,26}$ one in Semnan province, ${ }^{27}$ one in East Azerbaijan province, ${ }^{28}$ one in Kerman province, ${ }^{29}$ one in Tehran province, ${ }^{30}$ one in Shahroud city, ${ }^{31}$ and three in all states of Iran. ${ }^{32-34}$
Table 2

Basic characteristics of the studies included in the review.

\begin{tabular}{|c|c|c|c|c|c|}
\hline Order & Author/Year & Time period & Location & $\begin{array}{l}\text { ASR } \\
\text { (Males) }\end{array}$ & $\begin{array}{l}\text { ASR } \\
\text { (Females) }\end{array}$ \\
\hline 1 & Sadjadi, 2003 & 1996-1999 & Ardabil & 0.30 & 0.20 \\
\hline 2 & Babaei, 2005 & 1997-2001 & Semnan & 3.03 & 1.09 \\
\hline 3 & Sadjadi, 2007 & 1996-2000 & Kerman & 3.60 & 0.60 \\
\hline 4 & $\begin{array}{l}\text { Mehrabani, } \\
2008\end{array}$ & 1990-2005 & Fars & 1.16 & 0.10 \\
\hline \multirow[t]{3}{*}{5} & \multirow[t]{3}{*}{ Mousavi, 2008} & 2003-2004 & Iran & 2.21 & 0.26 \\
\hline & & 2004-2005 & Iran & 2.78 & 0.31 \\
\hline & & 2005-2006 & Iran & 3.04 & 0.43 \\
\hline 6 & Somi, 2008 & 2006-2007 & $\begin{array}{l}\text { East } \\
\text { Azerbaiian }\end{array}$ & 2.12 & 0.26 \\
\hline 7 & $\begin{array}{l}\text { Mohagheghi, } \\
2009\end{array}$ & 1998-2001 & Tehran & 5.30 & 0.90 \\
\hline 8 & Babaei, 2009 & 2004-2006 & Ardabil & 1.80 & 0.30 \\
\hline 9 & $\begin{array}{l}\text { Masoompour, } \\
2011\end{array}$ & 1998-2002 & Fars & 1.00 & 0.30 \\
\hline 10 & Fateh, 2013 & $2001-2010$ & Shahroud & 3.77 & 0.58 \\
\hline 11 & Roshandel, 2014 & 2012 & Iran & 3.80 & 0.60 \\
\hline \multirow[t]{3}{*}{12} & Masoompour, & 1985-1989 & Fars & 3.20 & - \\
\hline & \multirow[t]{2}{*}{2016} & 1998-2002 & Fars & 1.00 & - \\
\hline & & 2007-2010 & Fars & 3.93 & - \\
\hline 13 & Almasi, 2016 & 2012 & Iran & 3.80 & 0.60 \\
\hline
\end{tabular}

\subsection{The results of individual studies}

The highest ASR (5.30 per 100,000) of males was reported from Tehran province between 1998 to $2001^{30}$ and for females (1.09 per 100,000) was reported from Semnan province between 1997 and $2001,{ }^{27}$ while the lowest ASR in males was reported from Ardabil province between 1996 and $1999(0.3 \text { per 100,000) })^{25}$ and for females 


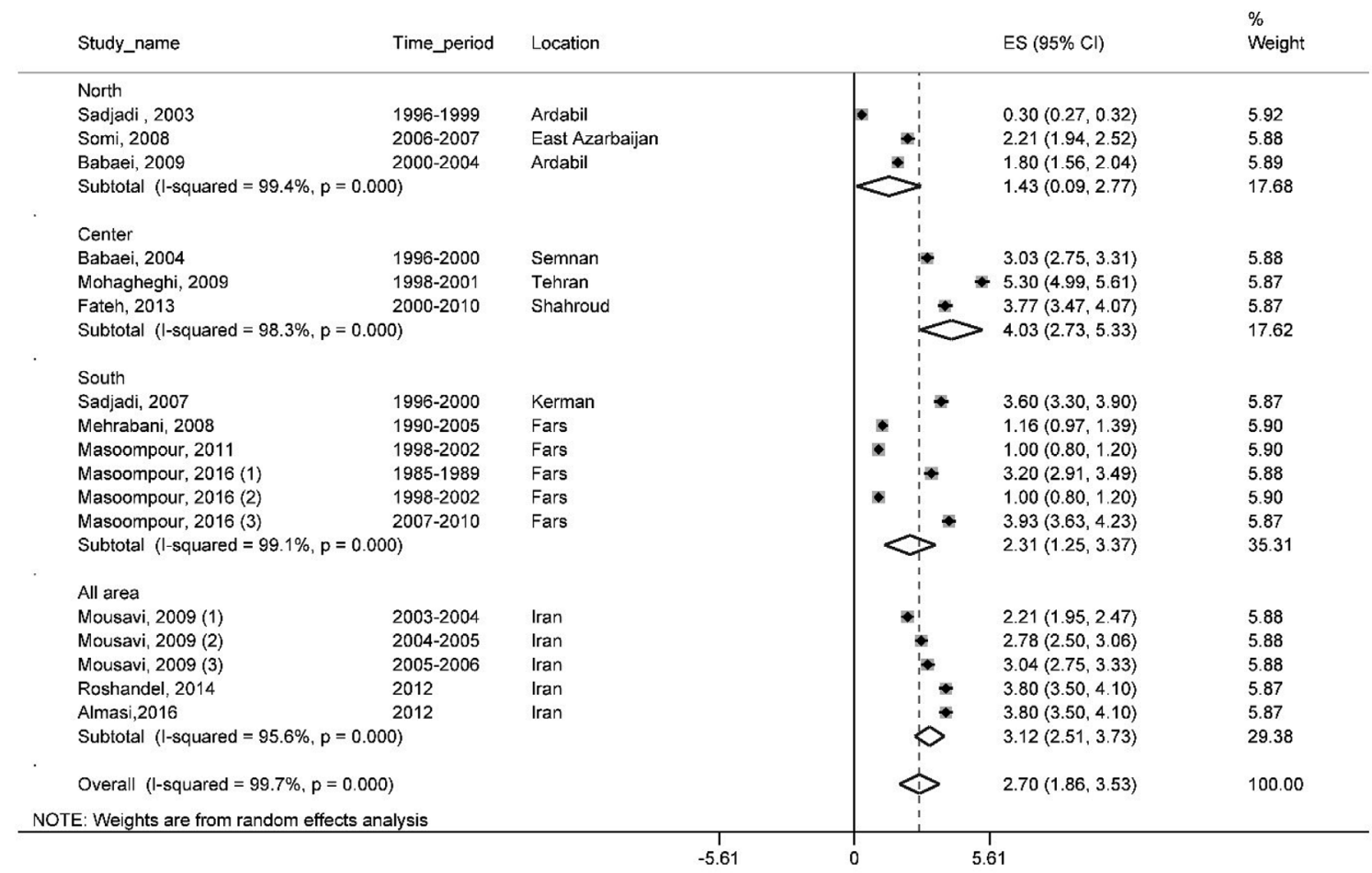

Fig. 2. Forest plot of the random-effect meta-analysis for age standardized incidence rates of laryngeal cancer in males in Iran.

from Fars province between 1990 and 2005 (0.1 per 100,000). ${ }^{22}$

\subsection{The results of meta-analysis}

The ASR of LaC was $2.70,95 \%$ CI (1.86-3.53) for males and 0.46 , $95 \%$ CI $(0.31-0.61)$ in females. This study showed the male to female sex ASR ratio is 5.86 (95\% CI; 4.29-8.02). The heterogeneity of the studies was demonstrated by Cochran's test $(\mathrm{Q}=5116.17, \mathrm{df}=16$, $\left.\mathrm{I}^{2}=99.7 \%, \mathrm{p}<0.001\right)$ for males and $(\mathrm{Q}=6147.2, \mathrm{df}=13$, $\left.\mathrm{I}^{2}=99.8 \%, \mathrm{p}<0.001\right)$ for females. The results of the random-effect meta-analysis for ASRs of LaC for males in Iran has been represented in Fig. 2 and for females in Fig. 3.

\subsection{Meta-regression}

Results of meta-regression showed a significant association between publication year and ASR of LaC in males. Thus, year of study is a cause of variability in results (Reg Coef $=0.067, p=0.006$ ). This association not statistically significant for females (Reg Coef $=0.048, p=0.077$ ) According to results, an increasing ASR of LaC across the study period was observed. Results of meta-regression has been show in Figs. 4 and 5 for males and females, respectively.

\subsection{Publication bias}

Publication bias was assessed using Egger's tests. ${ }^{35}$ Results of Egger's tests showed lack of publication bias. $(p=0.149$ for males and $P=0.225$ for females).

\section{Discussion}

This study aims to investigate the incidence of laC in Iran through a systematic and meta-analysis review. Results of the present study show that the ASR of laC among Iranian men is 2.62 per 100,000 and among Iranian women is 0.46 per 100,000 . According to the results, the incidence rate of laC among Iranian men and women is lower compared to other countries. Moreover, results indicate that countries in Western
Asia have higher incidence rates of laC (ASR $=6.5$ in men and 0.9 in women per 100,000) and countries in Eastern Asia have lower incidence rates (ASR $=2.2$ in men and 0.2 in women per 100,000). ${ }^{36}$

Globally, the highest ASR of laC among men is observed in central and Eastern Europe and in Caribbean (ASR $=7.8$ and 7.9 per 100,000, respectively). Also, the highest ASR of laC among women is observed in Southern Caribbean Africa (ASR $=0.9$ per 100,000). On the other hand, Some Western African countries have the lowest ASR of laC for men and women (ASR $=1.4$ and 0.1 per 100,000, respectively). ${ }^{36}$ The difference in laC incidence in Iran and other countries can be due to the level of income, environmental exposures, diagnostic methods, and lifestyle. ${ }^{37-40}$

Smoking and alcohol consumption are found to be the major risk factors for the high incidence of laC. According to a study conducted on head and neck cancers, the risk of these cancers was 6.5 times higher for smokers than non-smokers. ${ }^{41}$ Human papillomavirus (HPV) and Epstein-Barr virus (EBV) has been identified as other important risk factors for development of laC. According to studies, HPV infection has been associated with most head and neck cancers. ${ }^{42} \mathrm{EBV}$ is also a more common risk factor in Asian countries. ${ }^{43}$ Different diagnostic and recording techniques in various countries may result to a different and inaccurate incidence rate of laC.

According to the results of this study, the highest age ASR of laC in Iranian men is observed in Tehran province (ASR $=5.3$ per 100 thousand). The high incidence rate of $\mathrm{laC}$ in this province can be attributed to high prevalence of smoking, alcohol consumption, and other associated risk factors. ${ }^{44,45}$ According to studies, Tehran province is one of the areas with the highest prevalence of smoking in Iran. ${ }^{46}$ Also, the highest ASR of laC among Iranian women is observed in Semnan province (ASR $=1.09$ per 100 thousand). The high incidence rate of this cancer in Semnan province is probably due to women's exposure to risk factors such as smoking and incidence of HPV. ${ }^{47,48}$

Results from this study indicated that the lowest ASR of laC among Iranian men is observed in Fars province (ASR $=0.1$ per 100,000). The low incidence rate of laC in this province can be attributed to the demographic characteristics of people living in this area, differences in lifestyle, and the presence of other types of diseases and cancers. In Fras 


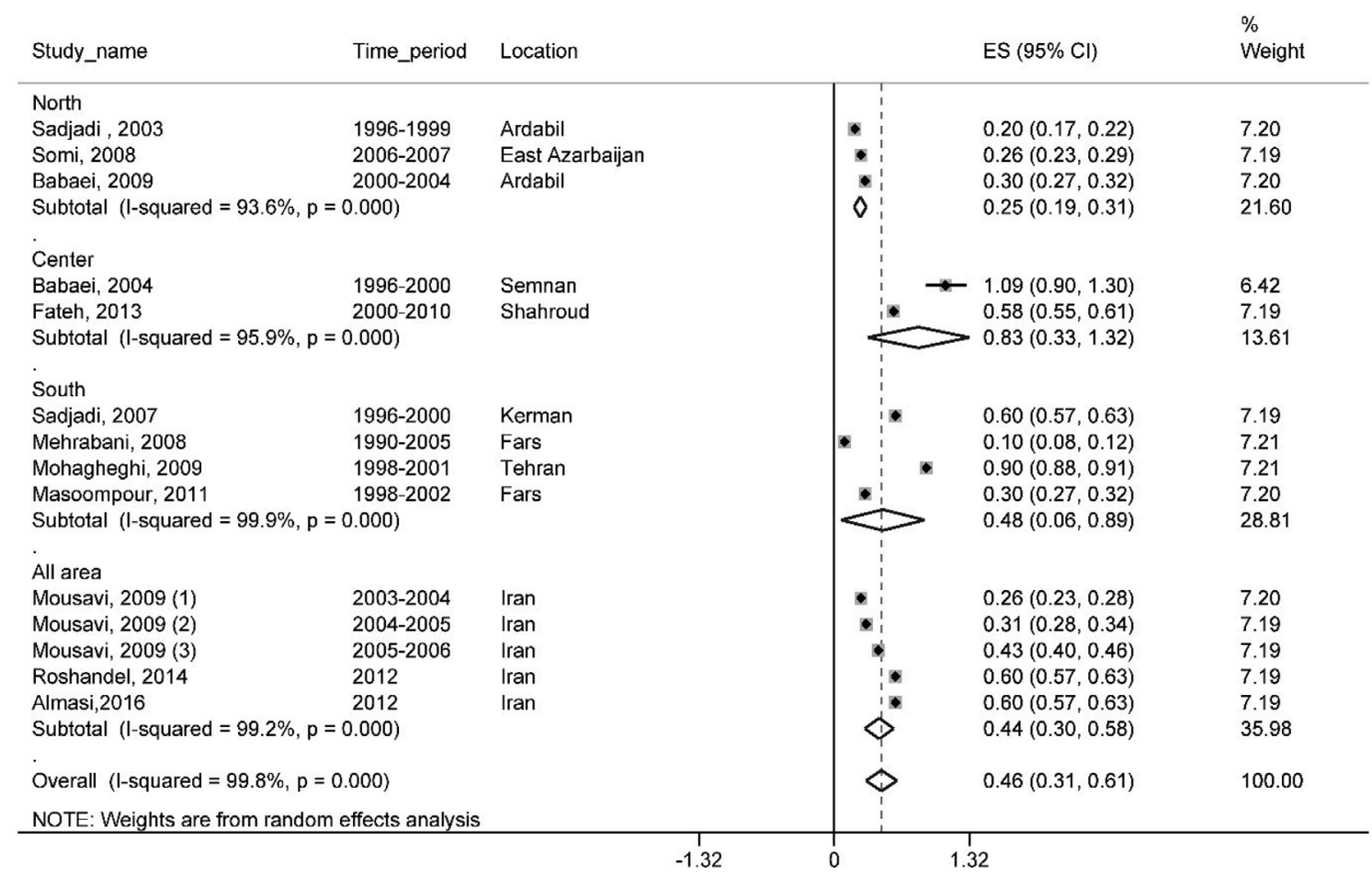

Fig. 3. Forest plot of the random-effect meta-analysis for age standardized incidence rates of laryngeal cancer in females in Iran.

province, gastric and bladder cancers have higher incidence rates among men. ${ }^{24}$ Also, the lowest ASR of laC among Iranian women is observed in East Azerbaijan Province (ASR $=0.1$ per 100,000). The low incidence rate of laC in this province can be attributed to the low prevalence of smoking and alcohol consumption among women in this region compared to other parts of the country. ${ }^{49-51}$ Moreover, other types of cancers such as breast, oesophageal, and skin cancers have higher incidence rates in this province. ${ }^{28}$

\section{Study limitations}

As with any systematic review study, the present study is limited in certain ways. The first drawback of the present study is lack of full access to all the required data bases. Perhaps including other studies could render different results. Another limitation and perhaps the most important one is missing sample size and failure to calculate the confidence interval for survival which did not allow proceeding with the meta-analysis stage.

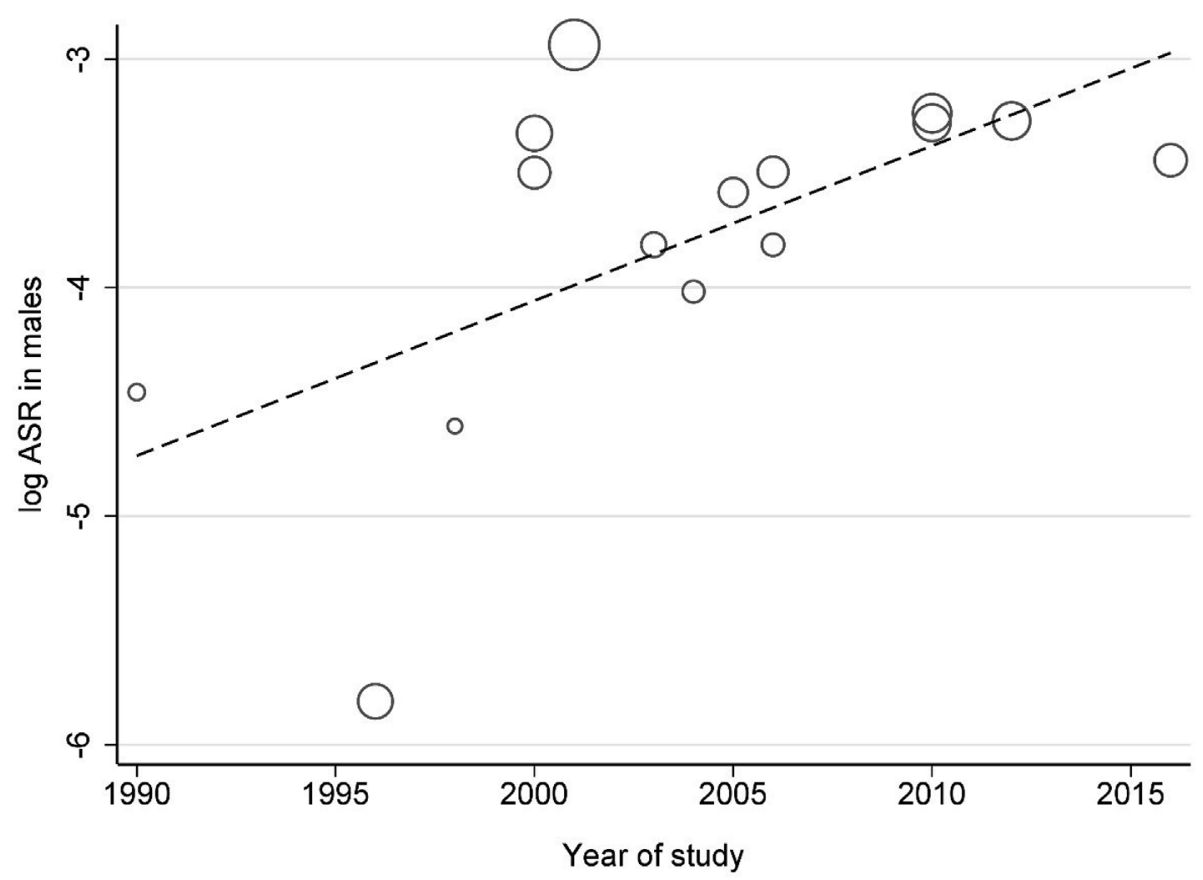

Fig. 4. Meta-regression plots of change in ASR of larynx cancer in males according to changes in continuous study moderator's year. 


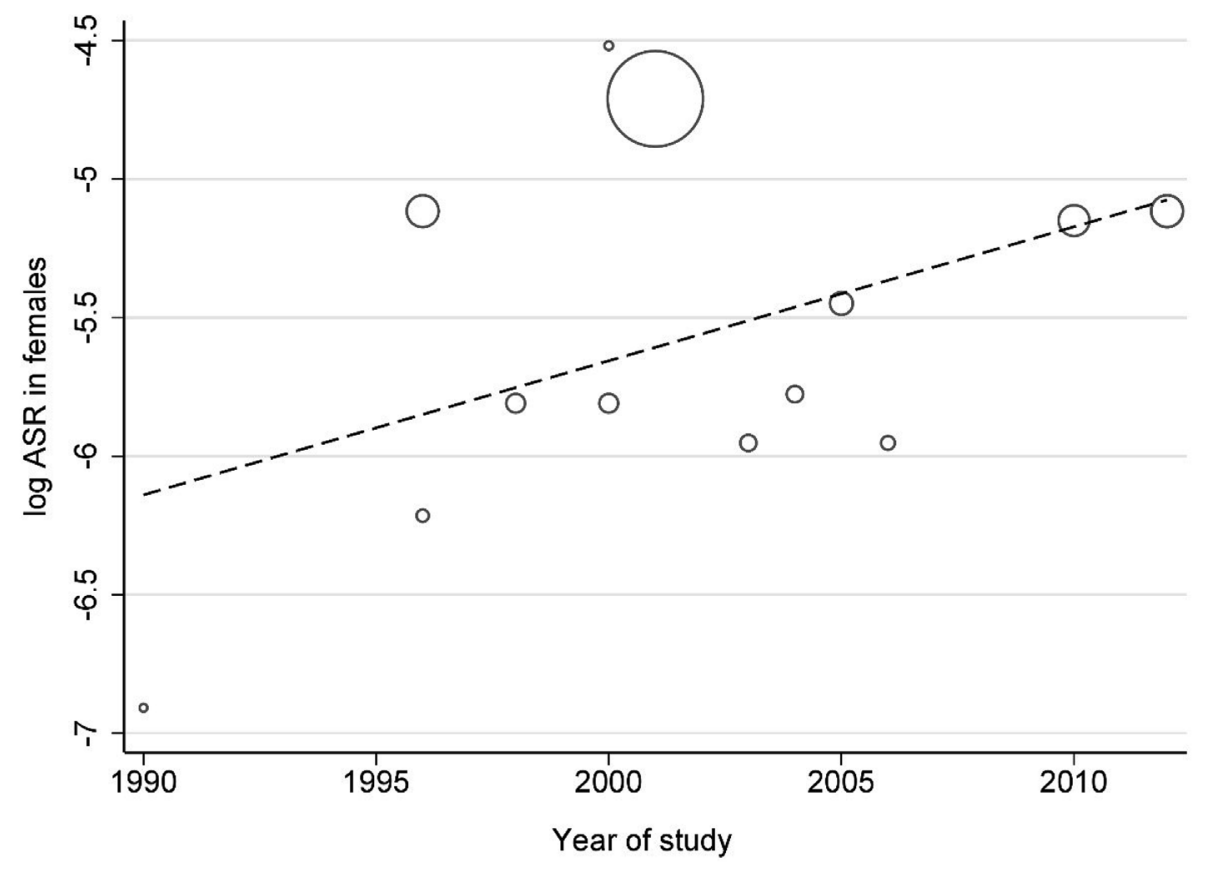

Fig. 5. Meta-regression plots of change in ASR of larynx cancer in females according to changes in continuous study moderator's year.

\section{Conclusion}

Although the incidence of laC in Iran is low, this study indicated a remarkable increasing trend in the prevalence of this cancer in Iran. Therefore, the number of new laC cases is expected to rise in future due to lifestyle changes and increased exposure to risk factors. Therefore, a comprehensive planning is needed to reduce the risk factors and prevent the incidence of laC in Iran.

\section{Authors' contributions}

S.H contributed in the conception of the study, conducted the study, analyze of data and prepared the draft. H.D contributed in the introduction of the study, drafted and revised the draft. H.N and E.A contributed in the conception of the study, conducted the study, revised the draft, approved the final version of the manuscript, and agreed for all aspects of the work. H.S and M. A contributed in the conception of the study, revised the draft, approved of the final version of the manuscript, and agreed for all aspects of the work. S.H and H.G contributed in the discussion of the study, conducted the study, revised the draft, approved of the final version of the manuscript, and agreed for all aspects of the work. All authors approved the final version of manuscript.

\section{Disclosure of interest}

The authors declare that they have no competing interest.

\section{Acknowledgement}

The present study was financially supported by Shiraz University of Medical Sciences, Shiraz, Iran (No: 96-01-42-16347).

\section{Appendix A. Supplementary data}

Supplementary data to this article can be found online at https:// doi.org/10.1016/j.cegh.2019.02.003.

\section{Appendix 1. Search strategy in PubMed}

\#1 "Laryngeal Neoplasms" [Mesh] OR "cancer of larynx" [Title/ Abstract] OR "larynx cancer" [Title/Abstract] OR "Neoplasms" [Mesh]. \#2 "age standardized rate" [Title/Abstract] OR "age standardized incidence rate" [Title/Abstract] OR "Epidemiology" [Title/Abstract] OR "incidence" [Title/Abstract].

\#3 "Islamic Republic of Iran" [Title/Abstract] OR "Iran" [Title/ Abstract].

\#4 \#1 AND \#2 AND \#3.

\section{References}

1. Megwalu UC, Sikora AG. Survival outcomes in advanced laryngeal cancer. JAMA Otolaryngol- Head Neck Surgery. 2014;140(9):855-860.

2. Siegel RL, Miller KD, Jemal A. Cancer statistics. 2016 CA A Cancer J Clin. 2016;66(1):7-30.

3. Markou K, Christoforidou A, Karasmanis I, et al. Laryngeal cancer: epidemiological data from Nuorthern Greece and review of the literature. Hippokratia. 2013;17(4):313-318.

4. Calkovsky V, Wallenfels P, Calkovska A, Hajtman A. Laryngeal cancer: 12-year experience of a single center. Adv Exp Med Biol. 2016:911:9-16.

5. de Jong MC, Pramana J, van der Wal JE, et al. CD44 expression predicts local recurrence after radiotherapy in larynx cancer. Clin Cancer Res : Off J Am Assoc Canc Res. 2010;16(21):5329-5338.

6. Rafferty MA, Fenton JE, Jones AS. The history, aetiology and epidemiology of laryngeal carcinoma. Clin Otolaryngol Allied Sci. 2001;26(6):442-446.

7. Joshi P, Dutta S, Chaturvedi P, Nair S. Head and neck cancers in developing countries. Rambam Maimonides Med J. 2014;5(2) e0009.

8. Bray I, Brennan P, Boffetta P. Projections of alcohol- and tobacco-related cancer mortality in Central Europe. Int J Cancer. 2000;87(1):122-128.

9. Kmet J, Mahboubi E. Esophageal cancer in the Caspian littoral of Iran: initial studies. Science (New York, NY). 1972;175(4024):846-853.

10. Mirzaei M, Hosseini S-A, Ghoncheh M, et al. Epidemiology and trend of head and neck cancers in Iran. Glob J Health Sci. 2016;8(1):189-193.

11. Fararouei M, Daneshi N, Mohammadianpanah M, Reza Tabatabaei H, ZareBandamiri M, Dianatinasab M. Factors predicting survival in patients with early stage laryngeal cancer: a cohort study between 2000 to 2015. J BUON : Off J Balkan Union of Oncol. 2017:22(4):996-1003.

12. Hassanipour S, Fathalipour M, Salehiniya H. The incidence of prostate cancer in Iran: a systematic review and meta-analysis. Prostate International. 2018;6(2):41-45.

13. Hassanipour S, Mokhtari A, Fathalipour M, Salehiniya H. The incidence of lung cancer in Iran: a systematic review and meta-analysis. World Canc Res J. 2017;4(4).

14. Hassanipour S, Namvar G, Fathalipour M, Salehiniya H. The incidence of kidney cancer in Iran: a systematic review and meta-analysis. Biomedicine. 2018;8(2):22-27.

15. Rezaianzadeh A, Hassanipour Azgomi S, Mokhtari AM, et al. The incidence of breast cancer in Iran: a systematic review and meta-analysis. J Anal Oncol. 
2016;5(4):139-145

16. Rezaianzadeh A, Jalali M, Maghsoudi A, Mokhtari AM, Azgomi SH, Dehghani SL. The overall 5-year survival rate of breast cancer among Iranian women: a systematic review and meta-Analysis of published studies. Breast Dis. 2017;37(2):63-68.

17. Rezaianzadeh A, Mokhtari AM, Hassanipour S, et al. The age-standardized incidence rate of ovarian cancer in iranian women: a systematic review and meta-analysis. Middle East J Canc. 2018;9(3):171-178.

18. Deshpande S, van Asselt A, Tomini F, et al. Preferred Reporting Items for Systematic Reviews and Meta-Analysis (PRISMA) Checklist. 2013; 2013.

19. Institute JB. The Joanna Briggs Institute Critical Appraisal Tools for Use in JBI Systematic Reviews Checklist for Analytical Cross Sectional Studies. North Adelaide, Australia: The Joanna Briggs Institute; 2017.

20. Harris RJ, Bradburn MJ, Deeks JJ, Harbord RM, Altman DG, Sterne JAC. metan: fixed- and random-effects meta-analysis. STATA J. 2008;8(1):3-28.

21. Bagos PG, Nikolopoulos GK. Mixed-Effects Poisson regression models for meta-analysis of follow-up studies with constant or varying durations. Int J Biostat. 2009;5(1):1557-1579.

22. Mehrabani D, Tabei SZ, Heydari ST, et al. Cancer occurrence in Fars province, southern Iran. Iran Red Crescent Med J. 2008;10(4):314-322.

23. Masoompour SM, Yarmohammadi H, Rezaianzadeh A, Lankarani KB. Cancer incidence in southern Iran, 1998-2002: results of population-based cancer registry. Cancer Epidemiol. 2011;35(5):e42-e47.

24. Masoompour SM, Lankarani KB, Honarvar B, Tabatabaee SH, Moghadami M, Khosravizadegan Z. Changing epidemiology of common cancers in Southern Iran, 2007-2010: a cross sectional study. PLoS One. 2016;11(5).

25. Sadjadi A, Malekzadeh R, Derakhshan MH, et al. Cancer occurrence in ardabil: results of a population-based cancer registry from Iran. Int $J$ Cancer. 2003;107(1):113-118

26. Babaei M, Jaafarzadeh H, Sadjadi AR, et al. Cancer incidence and mortality in ardabil: report of an ongoing population-based cancer registry in Iran, 2004-2006. Iran J Public Health. 2009;38(4):35-45.

27. Babai M, Mousavi S, Malek M, et al. Survey of cancer incidence during a 5-year (1998-2002) period in Semnan province. Koomesh. 2005;6(3):237-244

28. Somi MH, Farhang S, Mirinezhad SK, Naghashi S, Seif-Farshad M, Golzari M. Cancer in East Azerbaijan, Iran: results of a population-based cancer registry. Asian Pac J Cancer Prev APJCP. 2008;9(2):327-330.

29. Sadiadi A, Zahedi MJ, Moghadam SD, et al. The first population-based cancer survey in Kerman Province of Iran. Iran J Public Health. 2007;36(4):26-34.

30. Mohagheghi MA, Mosavi-Jarrahi A, Malekzadeh R, Parkin M. Cancer incidence in Tehran metropolis: the first report from the Tehran population-based cancer registry, 1998-2001. Arch Iran Med. 2009;12(1):15-23.

31. Fateh M, Emamian MH. Cancer incidence and trend analysis in Shahroud, Iran, 2000 - 2010. Iran J Cancer Prev. 2013;6(2):85-94.

32. Mousavi SM, Gouya MM, Ramazani R, Davanlou M, Hajsadeghi N, Seddighi Z. Cancer incidence and mortality in Iran. Ann Oncol. 2009;20(3):556-563.

33. Roshandel G, Boreiri M, Sadjadi A, Malekzadeh R. A diversity of cancer incidence and mortality in west Asian populations. Annal Glob Health. 2014;80(5):346-357.

34. Almasi Z, Mohammadian-Hafshejani A, Salehiniya H. Incidence, mortality, and epidemiological aspects of cancers in Iran; differences with the world data. J BUON :
Off J Balkan Union of Oncol. 2016;21(4):994-1004.

35. van Enst WA, Ochodo E, Scholten RJ, Hooft L, Leeflang MM. Investigation of publication bias in meta-analyses of diagnostic test accuracy: a meta-epidemiological study. BMC Med Res Methodol. 2014;14:70-74.

36. Ferlay J, Soerjomataram I, Dikshit R, et al. Cancer incidence and mortality worldwide: sources, methods and major patterns in GLOBOCAN 2012. Int J Cancer. 2015;136(5):E359-E386

37. Mohaghegh P, Yavari P, Akbari ME, Abadi A, Ahmadi F, Shormeij Z. Relationships between family levels of socioeconomic status and distribution of breast cancer risk factors. Iran J Cancer Prev. 2015;8(1):53-59.

38. Esmaelbeigi F, Hadji M, Harirchi I, Omranipour R, vand Rajabpour M, Zendehdel K. Factors affecting professional delay in diagnosis and treatment of oral cancer in Iran. Arch Iran Med. 2014;17(4):253-257.

39. Noonan B. Understanding the reasons why patients delay seeking treatment for oral cancer symptoms from a primary health care professional: an integrative literature review. Eur J Oncol Nurs : Off J Eur Oncol Nurs Soc. 2014;18(1):118-124.

40. Keramatinia A, Hassanipour S, Nazarzadeh M, et al. Correlation between nitrogen dioxide as an air pollution indicator and breast cancer: a systematic review and metaanalysis. Asian Pac J Cancer Prev APJCP. 2016;17(1):419-424.

41. Lewin F, Norell SE, Johansson $\mathrm{H}$, et al. Smoking tobacco, oral snuff, and alcohol in the etiology of squamous cell carcinoma of the head and neck: a population-based case-referent study in Sweden. Cancer. 1998;82(7):1367-1375.

42. Sankaranarayanan R, Masuyer E, Swaminathan R, Ferlay J, Whelan S. Head and neck cancer: a global perspective on epidemiology and prognosis. Anticancer Res. 1998;18(6b):4779-4786.

43. Settle K, Posner MR, Schumaker LM, et al. Racial survival disparity in head and neck cancer results from low prevalence of human papillomavirus infection in black oropharyngeal cancer patients. Cancer Prev Res. 2009;2(9):776-781 (Philadelphia, Pa).

44. Moosazadeh M, Ziaaddini H, Mirzazadeh A, Ashrafi-Asgarabad A, Haghdoost AA. Meta-analysis of smoking prevalence in Iran. Addiction \& Health. 2013;5(34):140-153.

45. Eskandarieh S, Hajebi A, Noroozi A, Haghdoost AA, Baneshi MR. Epidemiology of alcohol Abuse in Iran. Asia Pacific J Med Toxicol. 2014;3(Supplement 1):22.

46. Fotouhi A, KHABAZKHOUB M, HASHEMI H, Mohammad K. The Prevalence of Cigarette Smoking in Residents of Tehran. 2009; 2009.

47. Halimi L, Haghdoost AA, Mohammad Alizadeh S. Prevalence of cigarette smoking among Iranian women: a systematic review and meta-analysis. Med J Islam Repub Iran. 2013;27(3):132-140.

48. Rezvani MR, Shams M, Sayaadi M, Beigi P, Shams M. Assessment the prevalence of high-risk human papillomavirus types 16 and 18 in 15 to 45 years old women. Archiv Med Lab Sci. 2017;2(4).

49. Majidpour A, Hamidzadeh Arbaby Y, Abbasgholizadeh N, Salehy E. Prevalence and causes of tendency to cigarette smoking among students in ardabil university of medical Sciences. arumsj. 2005;5(3):266-270.

50. Moosazadeh M, Salami F, Movahednia M, Amiri MM, Afshari M. Prevalence of smoking in northwest Iran: a meta-analysis. Electron Physician. 2014;6(1):734-740.

51. Mokhtari AM, Riahi S, Fathalipour M, Delam H, Hashemnejad M, Hassanipour S. The age-standardized rate of female genital cancers in Iran: a systematic review and meta-analysis. tums-hayat. 2018;24(3):204-219. 